\title{
Formalization of Low-frequency Rectangular Electrical Connectors Design Method
}

\author{
V.I. Averchenkov ${ }^{1}$, A.V. Viluykha ${ }^{1}$, M.Yu. Rytov ${ }^{1}$ \\ aver@tu-bryansk.ru|alex-viluha@yandex.ru|rmy@tu-bryansk.ru \\ ${ }^{1}$ Bryansk State Technical University, Bryansk, Russia
}

The article deals with the design process of low-frequency rectangular electrical connectors and determining the position $C A D / C A E$-systems in it. The review of the actual literature shows that development trends of design and technological preparation of low-frequency rectangular electrical connectors production mean using CAD/CAM/CAE-systems. But at the moment these systems are used for solving partial issues. The authors formalize the empirical method of the design and systemize the factors, which influence the design process. As a result of the mentioned above actions, the working algorithm of the multipurpose CAD/CAE electrical connectors design system was obtained. The results of the research were applied to automize the design process of connectors housings.

Keywords: rectangular electrical connectors, CAD, design, design stages, CAD algorithms.

\section{Introduction}

Electrical connector is an electrical device designed for mechanical connection and disconnection of electrical circuits consisting of two or more parts (plug, socket) forming a detachable contact joint [7]. These devices are part of modern technical control systems in computer equipment, industrial equipment, automobiles, etc.

According to estimates given in $[20,21]$ the main development direction in the industry at present is the improvement of connector design characteristics (contact density increase, new original design types use), as well as improved reliability indicators (e.g. increasing the average service life from $12 \ldots 15$ years to 30 years).

Research in the field of design automation in relation to electrical connectors conducted by foreign colleagues is aimed at solving the following tasks: study of the contact process for a pair of connectors using models simulating the surface layer of materials [3]; use of numerical methods for the development of models meeting actual-use environmental conditions and external influences $[9,13]$.

At the same time, according to [20,21], the main objectives of domestic research in the field of electrical connectors design and production are: development of technologies for the production of new materials with improved characteristics, as well as their introduction into technological processes; increase of finished products resistance to external factors; implementation of modern means of computer-aided design and production planning.

Recent Russian research in the field of instrument manufacturing design automation include the works by A.L. Safonov [17] where the author proposes a computer-aided design system for rectangular electrical connectors developed on the basis of domestic Compas 3D CAD-system allowing to optimize the mass and dimensional parameters of Lira-type terminals, and also analyze the stationary temperature field of electrical connectors by finite element method. However, to calculate mechanical and electrical characteristics the author uses formalized empirical methods of calculation.

Also, G.Kh. Irzaev in his works $[10,11]$ offers solutions for evaluation automation and instrumental products design manufacturability optimization. The issues of automation equipment introduction in the process of design and calculation of instrumental products are touched upon in the works from the perspective of product manufacturability automation.

Other areas of domestic research in the field of design and production of electrical connectors are: development of software and hardware complexes for testing operational characteristics of the object of study [1,2], as well as issues of quality assurance of products and their components [16, 19].

Thus, the task of developing an integrated automation system for electrical connectors design is relevant in the view of modern $\mathrm{CAD} / \mathrm{CAE}$-systems functional capabilities development and will reduce time and labor costs for new types of products design and launch.

\section{Low-frequency rectangular electrical connectors design process analysis}

Based on the analysis of low-frequency rectangular electrical connectors empirical design methods, the authors developed a design algorithm which includes several stages (Fig. 1).

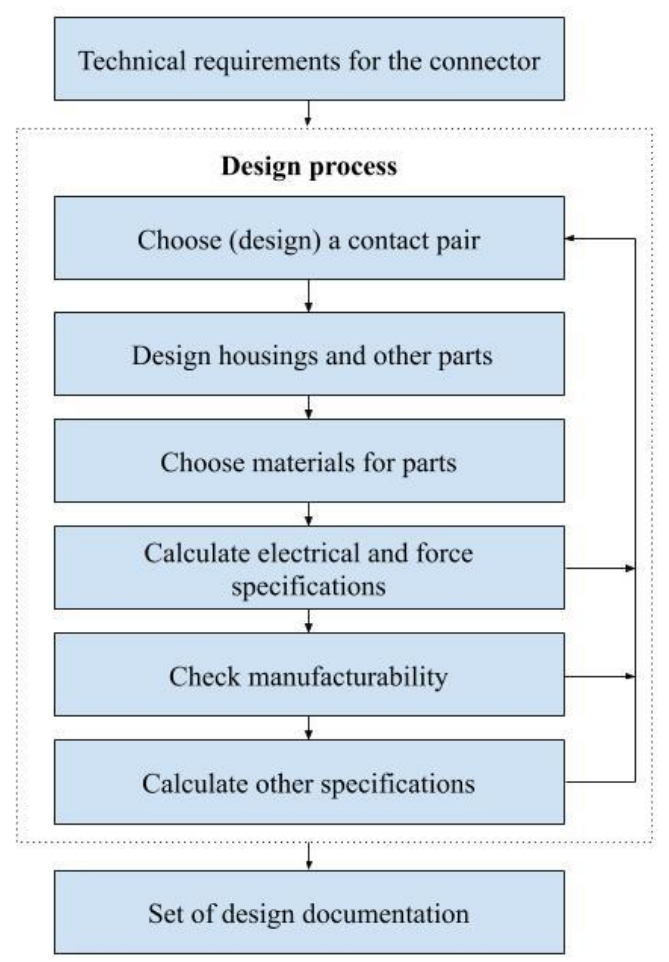

Fig. 1. Electrical connectors design stages

The design process for electrical connectors begins with the analysis of technical specification requirements. Based on [8], these requirements have been formalized (Table 1). 
Formalized data of technical specification

\begin{tabular}{|c|c|c|}
\hline Specifications & $\begin{array}{l}\text { Unit of } \\
\text { measure }\end{array}$ & Permissible values \\
\hline Current rating & A & according to the technical requirements \\
\hline Voltage rating & Volt & $\begin{array}{l}50,100,150,250,400,500,700,1000,1250,1500 \text { (according to } \\
\text { GOST } 23784-98, \text { p.5.3.7) }\end{array}$ \\
\hline Operating temp range & ${ }^{\circ} \mathrm{C}$ & according to the technical requirements \\
\hline Normal force & $\mathrm{N}$ & according to the technical requirements \\
\hline Max cycles & Quantity & $\begin{array}{l}\text { 100, 250, 500, 1000, 1500, } 2000 \text { (according to GOST 23784-98, } \\
\text { p.5.2.17) }\end{array}$ \\
\hline Type of mounting & - & according to the technical requirements \\
\hline Plating & - & according to GOST 9.303-84 \\
\hline Quantity of terminals & Quantity & according to the technical requirements \\
\hline Quantity of rows & Quantity & according to the technical requirements \\
\hline Pitch 1 & $\mathrm{~mm}$ & according to the technical requirements \\
\hline Pitch 2 & $\mathrm{~mm}$ & according to the technical requirements \\
\hline Terminal resistance & $\mathrm{m} \Omega$ & according to the technical requirements \\
\hline Isolation resistance & $\mathrm{M} \Omega$ & $500,1000,5000,10000$ (according to GOST 23784-98, p.5.3.5) \\
\hline Dielectric strength & Volt & according to the technical requirements \\
\hline Min storability time & years & $5,6,8,10,12,15$ (according to GOST $23784-98$, p.5.4.4) \\
\hline $\begin{array}{l}\text { Gamma-percentile operating time to } \\
\text { failure }\end{array}$ & hours & $\begin{array}{l}\text { 5000, 7500, 10000, 15000, 20000, 25000, } 50000 \text { (according to } \\
\text { GOST 23784-98, p.5.4.3) }\end{array}$ \\
\hline
\end{tabular}

The specified requirements from technical specification define the type of contact pair. Typical solutions are in most use.

At the next stage, the options for fixing the contact pair in the dielectric are studied and the materials are selected to ensure the required electromechanical parameters as stated in the technical specification.

The next stage is to check the developed design using design calculations. Design calculations are carried out in two ways:

1. Using analytical methods [12].

2. Using numerical methods.

At the next stage, specialists check the manufacturability of the components design which determines the possibility of making them at the manufacturing unit.

If the designed components of the connector meet the requirements of the technical specification, the performance characteristics of the connector shall be calculated.

Based on the algorithm, the authors developed a SADT model of the future integrated system (Fig. 2).

\section{Development of integrated CAD/CAE system of low-frequency rectangular electrical connectors design algorithm}

Analyzed [4] CAD- and CAE-systems allow to implement low-frequency rectangular electrical connectors design processes. However, in order to perform automated design calculations, product designers need to convert models for CAE systems or modules manually, which significantly increases the design period. The solution to the problem described above is to use parameterized 3D models with pre-defined scenarios for calculating the required characteristics.

To implement this task, systems with the following tools are required: means of calculation of mechanical, electrical, thermal characteristics of connectors by finite elements method; API interface. These tools can be found in such foreign systems as Autodesk Inventor, SolidWorks, Creo Parametric, Catia, and in such domestic systems as Compas 3D, T-Flex CAD, therefore the proposed computer-assisted design algorithm (Fig. 3) can be implemented in any of these systems.

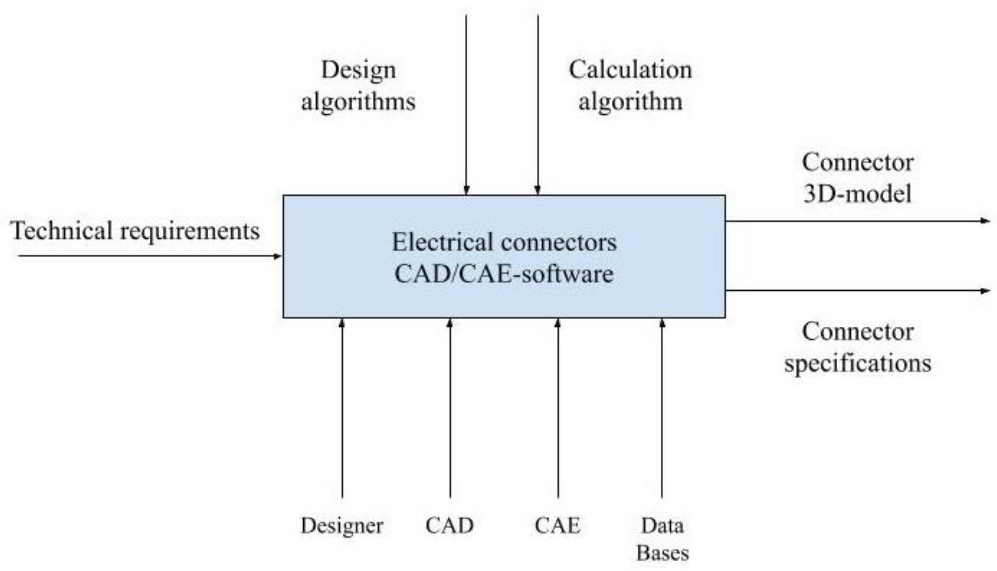

Fig. 2. SADT model of the system under development 


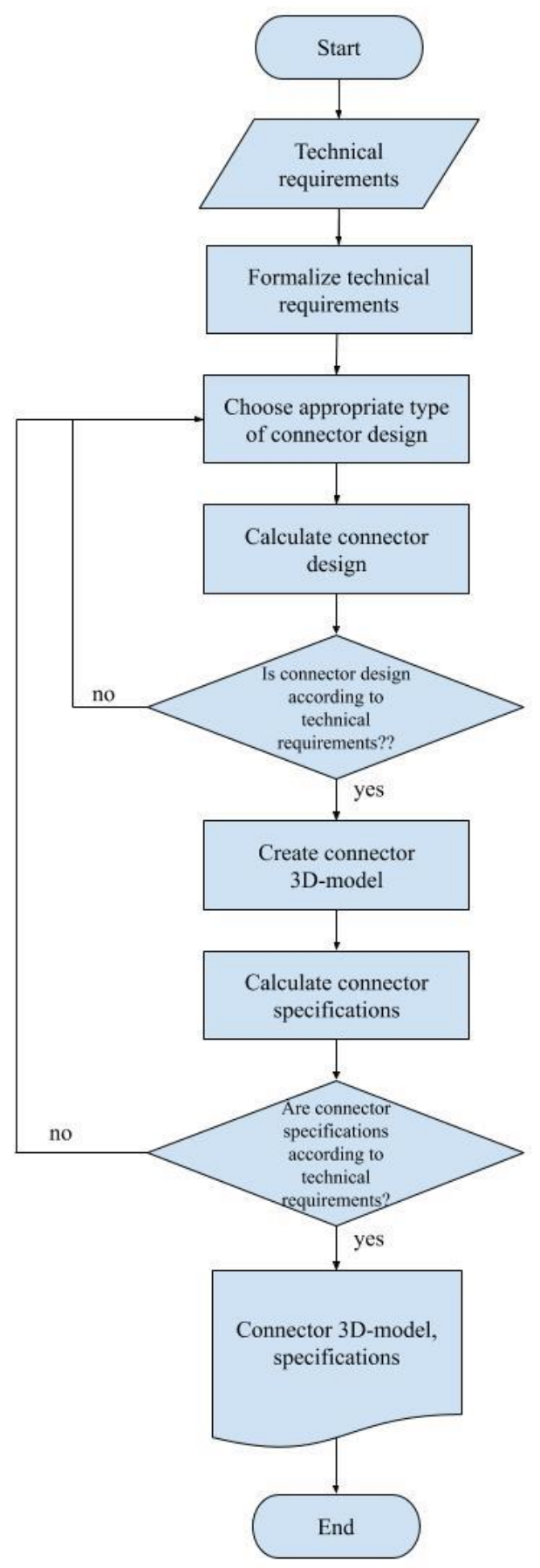

Fig. 3. Low-frequency electrical connectors design stages

The algorithm of computer-assisted design system includes several stages.

At the first stage, the user (design engineer) enters data from the technical specification mentioned in Table 1.

At the next stage, an optimal contact pair satisfying the requirements of the technical specification is selected and its design parameters are calculated. The most appropriate option is offered to the designer to continue the design procedures interactively.

Case dimensions are calculated for the selected contact pair. If the results of the calculations are consistent with the requirements of the technical specification, the values of the basic parameters are entered into the database together with the initial data, as a new project. If necessary, this data can be used again.
Further, the resulting design parameters are transferred to the CAD system where 3D models are generated from the typical designs database using API interface. The result of computerassisted design is a 3D model of the product that meets the requirements of the technical specification.

The next stage is automated calculation of operational characteristics using the 3D models obtained in the previous stage, which is performed in the following order:

1. Breakdown distance between wiring tails (medium air).

2. Breakdown distance between terminals (in dielectric).

3. Permissible current through min section of the contact pair.

4. Contact elastic element stiffness.

5. Normal force.

6. Contact withdrawal force.

7. Connector engaging force.

8. Terminal resistance.

9. Contact bending moment.

10. Contact cross section moment resistance.

11. Strength condition verification.

12. Maximum operating temperature.

13. Permissible hours in service.

Calculation stages 1-3 and 13 are implemented using the algorithms set out in [11], while steps 4-12 are performed via automation of scenarios for typical design 3D models calculations using CAE module.

If the resulting structure meets the requirements of the technical specification, the parameters from the remaining groups are calculated, or the design process returns to the dimensions calculation stage.

The result of the system operation is 3D models for a pair of connectors (plug, socket) and the calculated values of their characteristics.

\section{Example of parameterized 3D model for connectors components development}

To implement the above algorithm of the integrated system, parameterized 3D models are required, which are the basis for the generation of the product meeting the requirements of the technical specification.

The first stage is to develop case-type components. The key feature of these components is high variability of the overall dimensions. Figure 4 shows a parametric 3D model of the component developed in SolidWorks (the implementation program was selected according to the potential consumer of the system being developed).

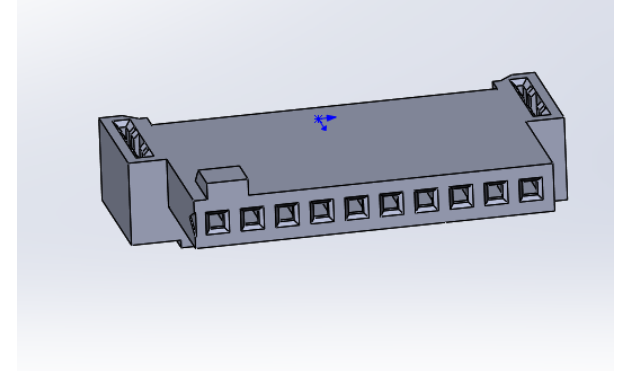

Fig. 4. Parametric 3D model

The key parameter which defines the component design, is the number of pins. The value of this parameter is stored in the Equations menu and indicated by the word "Quantity of terminals".

To connect to SolidWorks environment, we create an object of SldWorks swApp class [14]. The parameterized model is accessed through an object of the ModelDoc2 class. The loop and GetEquationMgr () function were used to find the necessary parameter to change the model structure. 
The view of the implemented WindowsForms interface for user interaction is shown in Figure 5.

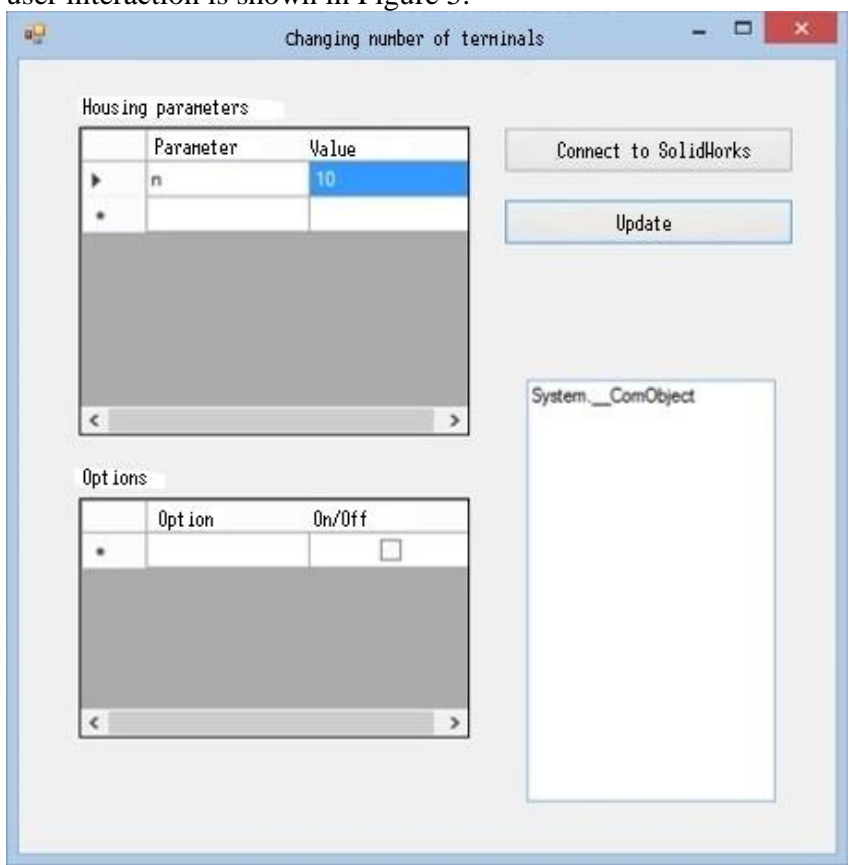

Fig. 5. Interface of the developed application

The numeric value of the parameter is changed by typing text in the "Value" field. The quantity of terminals was changed from 10 to 20. Next, model parameters are updated. The results of the application operation are presented in Fig. 6.

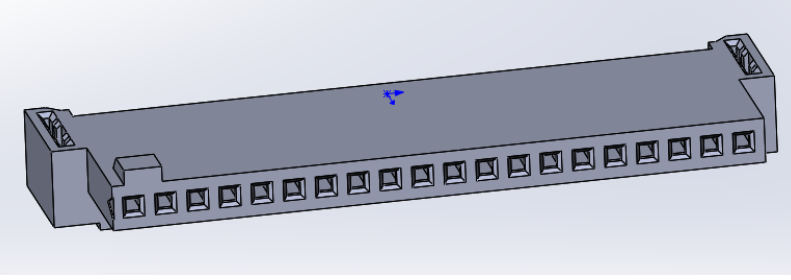

Figure 6. The result of software operation

The operation of changing the number of terminals using developed application takes less than 30 seconds, while a designer would need at least 30 minutes to develop a new model. The implementation of this technology within the proposed system will significantly reduce the design period.

\section{Conclusion}

The design of low-frequency rectangular electrical connectors is a complex, iterative and multi-factor process each stage of which involves a number of tasks that can be formalized and converted to algorithms.

To reduce the technological gap of the domestic instrument manufacturing industry, it is necessary to take full advantage of modern multifunctional CAD/CAM/CAE systems.

However, the electrical connectors design process includes a simultaneous work on several specific problems from various subject areas that are not currently taken into account in large CAD/CAM/CAE systems.

This contradiction can be solved by using the proposed $\mathrm{CAD} / \mathrm{CAE}$ system which will reduce the time spent on design calculations and optimize the new products development process.

\section{References}

[1] Akulov P.A., Petreshin D.I. Automation of control operation of electrical connectors verification // Automation. Modern technologies. -2019. - Vol. 73. - №. 6. P. 257-262.

[2] Akulov P.A., Petreshin D.I. Automated system of electrical connectors testing for wear resistance // Mechatronics, Automation and Robotics. -2019. -№ 3. P. 151-154.

[3] Albers A. Modeling and design of contacts in electrical connectors/ A. Albers, P. Martin, B. Lorentz// International conference on engineering design; Technical university of Denmark. -Kgs. Lyngby, -2011.

[4] Vasiliev V.A., Kalmykova M.A. Analysis and choice of software products for engineering problems solution in instrument engineering // Modern engineering and technologies. -2013. -№ 3 [Electronic resource]. URL: http://technology.snauka.ru/2013/03/1702 (date of access: 13.08.2019).

[5] GOST 2.103-2013 Unified system of design documentation (ESKD). Development stages (with Amendment) [Text]. [Electronic resource]. URL: http://docs.cntd.ru/document/1200115351 (date of access: 07.05.2019).

[6] GOST 14312-79 Electrical terminals. Terms and definitions [Text]. [Electronic resource]. URL: http://docs.cntd.ru/document/1200011348 (date of access: 07.05.2019).

[7] GOST 21962-76 Electrical connectors. Terms and definitions [Text]. [Electronic resource]. URL: http://docs.cntd.ru/document/gost-2192-76 (date of access: 07.11.2018).

[8] GOST 23784-98 Low-frequency connectors low-voltage and combined. General specifications [Text]. [Electronic resource]. URL: http://docs.cntd.ru/document/1200031615 (date of access: 07.05.2019).

[9] Guan L. Modeling and Analysis of Electrical Connectors in Salt Spray Environment/ L.Guan, Y. Li, Ch. Feng, Q. Li, Y. Zhou, J. Gao// International Conference on Computer Modeling, Simulation and Algorithm. -2018.

[10] Irzayev G.Kh. Design selection model based on quantitative criteria in the system of ensuring manufacturability of products // Systems. Methods. Technologies. -2014. -№ 2 (22). P.108-113.

[11] Irzayev, G.Kh. Numerical method of radioelectronic device design optimization based on manufacturability criterion/ Bulletin of Dagestan State Technical University. Technical Sciences. - 2013. - №1 (28) [Electronic resource]. URL: https://cyberleninka.ru/article/v/chislennyy-metodoptimizatsii-konstruktsii-radioelektronnogo-ustroystva-pokriteriyu-tehnologichnosti (date of access: 25.08.2019).

[12] Levin, A.P. Electrical connectors terminals in electronic equipment (calculation and design). Moscow, "Soviet Radio" publishing house, 1972, 216p.

[13] Luo Y. Numerical analysis and experimental verification on stress field of electrical connector contact[J] / Y.Luo, J.Yang, X.Liu, X.Li // Chinese Journal of Engineering Design. -2016.

[14] Malpass L., SolidWorks API Series 1: Programming \& Automation/ - January 9, 2014. -166 pages.

[15] Pivovarov V. Analysis of global development trends and production problems of electric connectors/ V. Pivovarov, L. Safonov, I. Khokhlov // Components and Technologies. -2007. -№2. - P.94-97.

[16] Podmasteriev K.V. Practical application of risk assessment model for quality control of electrical connectors contact pairs /K.V. Podmasteriev, V.V. Markov, A.V. Smetannikov, A.N. Lukyanchikov // Fundamental and 
Applied Problems of Engineering and Technology. 2017. № 6 (326). P. 172-180

[17] Safonov A.L. Automation of electrical connectors design based on formalization and standardizing of design procedures: Dissertation abstract in candidacy for an academic degree of Ph.D. in technical sciences: 05.13.12/ Safonov Alexander Leonidovich; BSTU. - Bryansk, 2010. $22 \mathrm{p}$.

[18] Safonov A.L. Optimization of electrical connectors structural elements / Software products and systems. -2009. -№4 [Electronic resource]. URL: https://cyberleninka.ru/article/v/optimizatsiya-elementovkonstruktsii-elektricheskih-soediniteley (date of access: 25.08.2019)

[19] Safonov A.L., Safonov L.I. Rectangular electrical connectors / A.L. Safonov, L.I. Safonov - St. Petersburg.: LLC "Finstreet Publishing", 2011. — 328c.: ill., table. Safonov A., Safonov L. Rectangular electrical connectors. Modern tendencies of statistical methods development for product quality management // Technologies in electronic industry. -2013. -№ 7 (67). P. 86-91.

[20] Utkin G.I. Analysis of the state of electrical connectors industrial production and tendencies of its development/ G.I. Utkin// Fundamental and applied problems of engineering and technology. - 2012. - № 3-3 (293). - P. 134139.

[21] Yeryomin, A. Ways rectangular low-frequency connectors production development in Russia/ A. Yeryomin, A. Kiselyov, A. Shadrin // Modern electronics. -2013. - № 6 [Electronic resource]. URL: http://www.ptkgroup.ru/assets/files/catalog/Ерёмин_ПроТ ехКомплект_03.pdf (date of access: 13.08.2019). 